\title{
Intravascular large cell lymphoma: Clinicopathological and immunohistochemical description of a case
}

\section{Branko DOŽı́́ ${ }^{1,2}$ \\ Dubravka CVETKOVIĆ ${ }^{1}$ Marko DOŽı́́ ${ }^{3}$ Ljiljana BUMBAŠIREVIĆ ${ }^{4}$}

'INSTITUTE OF PATHOLOGY, MEDICAL FACULTY, UNIVERSITY OF BELGRADE, BELGRADE, SERBIA AND MONTENEGRO ${ }^{2}$ INSTITUTE OF ORAL PATHOLOGY, STOMATOLOGICAL FACULTY, UNIVERSITY OF BELGRADE, BELGRADE,

SERBIA AND MONTENEGRO

${ }^{3}$ INSTITUTE OF ONCOLOGY AND RADIOLOGY OF SERBIA, BELGRADE, SERBIA AND MONTENEGRO

${ }^{4}$ INSTITUTE OF NEUROLOGY, MEDICAL FACULTY, UNIVERSITY OF BELGRADE, BELGRADE, SERBIA AND MONTENEGRO

\begin{abstract}
A 51-year-old female patient was admitted to the Neurological clinic because of motor seizures with myoclonus of the right hand and right side of the face. The results of initial brain CT scan, chest X rays, EEG, ultrasonography of the great blood vessels and laboratory tests made in another hospital were unremarkable. Because of repeated partial seizures, transient aphasic disturbances, urinary sphincter disturbances and periodic low-grade fever the patient was transferred to our hospital four months after the disease onset. Laboratory tests and NMR suggested a nonspecific disseminated viral encephalitis. After administration of Endoxan she was ambulatory for several weeks and then became increasingly exhausted, confused, febrile, dyspneic, tachypneic and developed a shock status with hepatorenal insufficiency. She died after 7 months of disease duration. Postmortem examination revealed intravascular collections of large atypical lymphoid cells of $B$ cell line. Blood vessels changed in this way were common in the brain and rare in other organs including skin, lungs, heart, liver, spleen and digestive system. They were not found in the lymph nodes and bone marrow. A biopsy was not done because of absence of symptomatic and swollen tissues. However, correlation of clinical feature and postmortem findings shows that absence of clinical manifestations in an organ does not mean lack of microscopic pathological changes and biopsy should be done regardless of absence of clinical signs. This case shows that intravascular lymphoma may mimic vasculitis or disseminated nonspecific viral encephalitis.
\end{abstract}

KEY WORDS: Intravascular Lymphoma; Neoplastic Angioendothelomatosis; Angiotropic Large Cell Lymphoma

\section{INTRODUCTION}

ntravascular lymphoma (IVL) is a very rare form of nonHodgkin's lymphoma, characterized by widespread intravascular proliferation of malignant lymphoid cells often presenting with nonspecific clinical features and extremely poor prognosis. The terminology used to describe this entity is variable and suggests endothelial origin of neoplastic cells. The most used term is neoplastic (malignant) angioendotheliomatosis or angioendotheliosis. However, there is conclusive evidence that this tumor represents a special form of malignant lymphoma (1-

Address correspondence to:

Prof. Dr. Dubravka Cvetković, Institute of Pathology, Medical Faculty, University of Belgrade, Dr Subotića 1, P.0.Box 168, 11000 Belgrade, Serbia and Montenegro; e-mail: dozic@eunet.yu

The manuscript was received: 27. 01. 2003

Provisionally accepted: 14.03 .2003

Accepted for publication: 17. 03. 2003
4) and therefore intravascular lymphoma is the most appropriate name for this disease. Although not specifically recognized by the Revised European-American Classification of Lymphoid neoplasms, it likely will appear as a subtype of large B-cell lymphoma in the upcoming WHO classification (5). This entity was first described as a neoplasia predominantly of the skin blood vessels (6). However, subsequently reported cases have shown that IVL is a rather systemic disease involving most frequently skin and central nervous system (CNS) $(6,7,8)$ and very rare exclusively CNS (4).

\section{CASE REPORT}

A 51-year-old female patient was admitted to the Neurological clinic in July 2001 because of motor seizures with myoclonus of the right hand and right side of the face followed by secondary generalization. That was the first seizure onset with no other relevant past medical history. At the first admission she was found to have no neurological disturbances. Results of chest $\mathrm{X}$ rays, EEG, 
Dožić B.

ultrasonography of the great blood vessels and laboratory tests made in another hospital were unremarkable as was well as initial brain CT scan. Because of repeated partial seizures, transient aphasic disturbances, anal and urinary sphincters disturbances and periodical low-grade fever the patient was transferred to our hospital four months after the disease onset. At admission she showed right hemiparesis, aphasia, and sphincter disturbances. Examination of CSF after lumbar puncture showed a total protein of $0.70 \mathrm{~g} / \mathrm{l}$, and IEF normal. Blood and liquor cultures showed no growth. Viruses in blood and CSF (HIV, HSV, CMV, EBV and varicella-zoster), as well as Toxoplasma gondii and Mycoplasma pneumoniae were negative.

EEG showed a global deceleration with focal attenuation over left fronto-temporal region. Laboratory investigation revealed increased level of AST and ALT. NMR suggested a nonspecific disseminated viral encephalitis. After administration of Endoxan she was ambulatory for several weeks and then became increasingly exhausted, confused, febrile, dyspneic, tachypneic and developed a shock status with hepatorenal insufficiency. CT showed multifocal hypodense zones. She died after 7 months of disease duration.

Autopsy was done 20 hours after the patient's death. The brain and the blocks of the other organs were fixed by immersion in $10 \%$ formalin and embedded in paraffin. The brain sections were stained with hematoxilyn-eosin (HE), luxol-fast-blue-NissI (LFBNissl) for myelin, periodic-acid-Schiff (PAS), Sudan III, Gomori and Palmgren silver impregnation. Immunohistochemical staining was performed on paraffin sections by the peroxyase-antiperoxydase (PAP) technique using DAKO antisera raised against the following antigens: glial fibrillary acidic protein (GFAP), S-100 protein, and monoclonal antibodies raised against the leukocyte common antigen (LCA), CD45, CD20, CD45RA, CD45R0, CD3, and factor-VIII-related antigen (FVIIIRA).

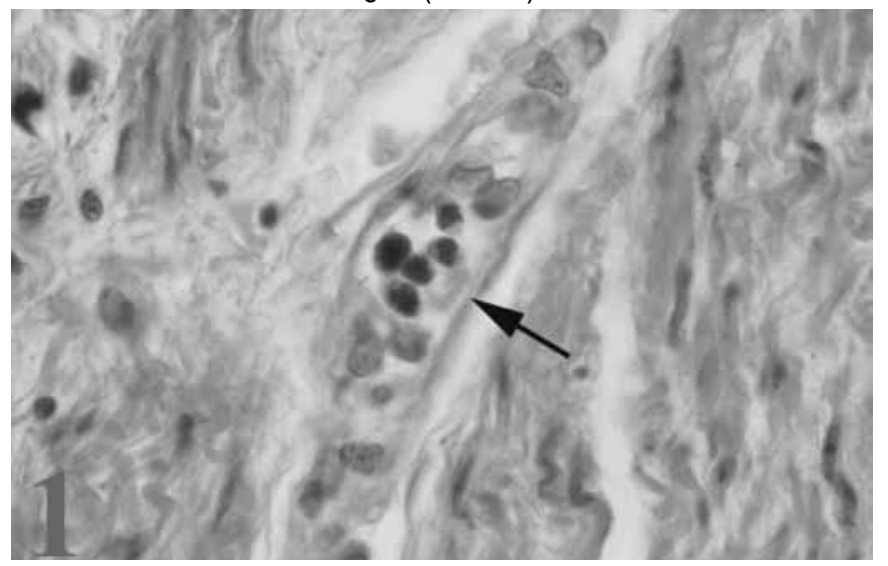

Figure 1. Large neoplastic lymphoid cells with irregular hyperchromatic nucleus are present within intestinal blood vessel. HE, x400

Grossly, except of anemia of all organs including brain and skin, other relevant changes were not found. Microscopically, in the rare small blood vessels of organs outside the central nervous system, including skin, lungs, heart, liver, spleen and digestive system occlusion by neoplastic cells was found (Figure 1). In the blood vessels of lymph nodes and bone marrow malignant cells were not present. Lymph nodes were not enlarged.

Microscopically, in many small and medium blood vessels there were intraluminal collections of atypical cells, which partially or completely obstructed the vascular lumina (Figures 2, 3).

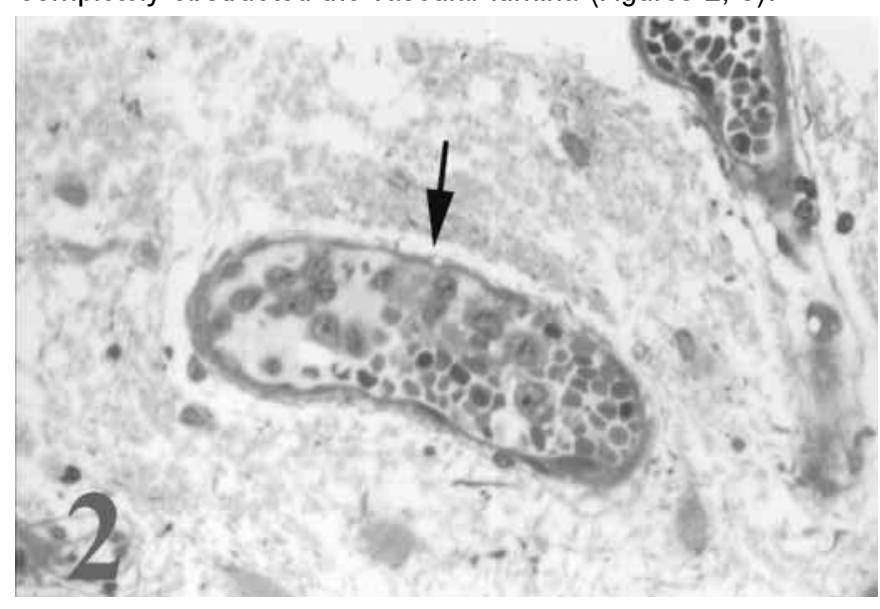

Figure 2. A cerebral blood vessel partially filled with neoplastic cells. Semithin section, epon, toluidin blue, $x 400$

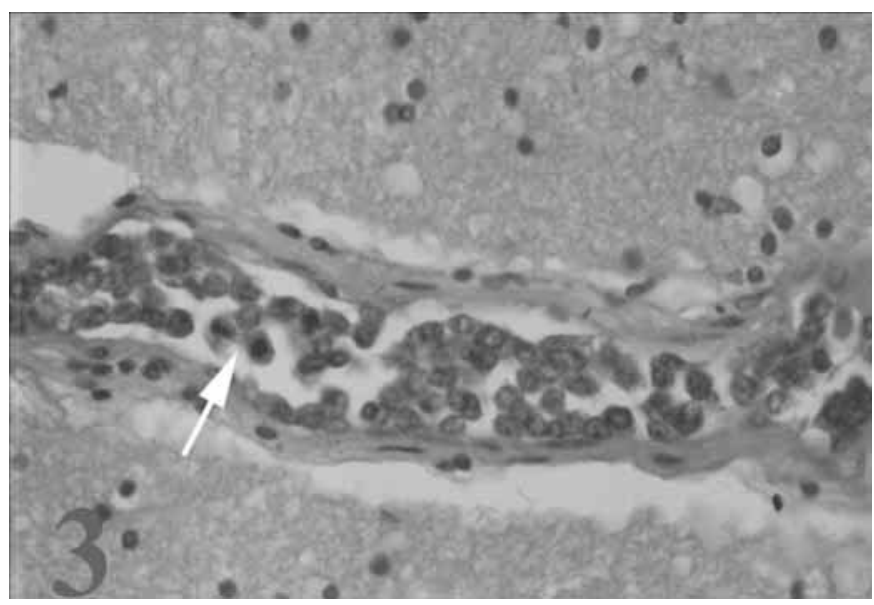

Figure 3. A blood vessel in the cerebral white matter plugged by tumor cells. Occasional pathological mitosis is seen (arrow). HE, x400

These cells are oval or round with small to moderate amount of amphophilic cytoplasm. The nuclei are variable in size, occasionally irregular, hyperchromatic with a small visible nucleolus in some of them (Figure 3). Pathological mitoses were occasionally present (Figure 3 , arrow). In the vicinity of occluded blood vessels there are small zones of spongy edema, reactive gliosis and foci of predominantly selective necrosis (Figure 4).

Immunohistochemically, tumor cells were positive for LCA and CD 20 marker for $B$ lymphocytes (Figure $5 a, b)$, and negative for T-cell markers CD45R0 and CD3. On the basis of histological and immunohistochemical findings the diagnosis of intravascular (angiotropic) large cell lymphoma of B-cell lineage was made. 


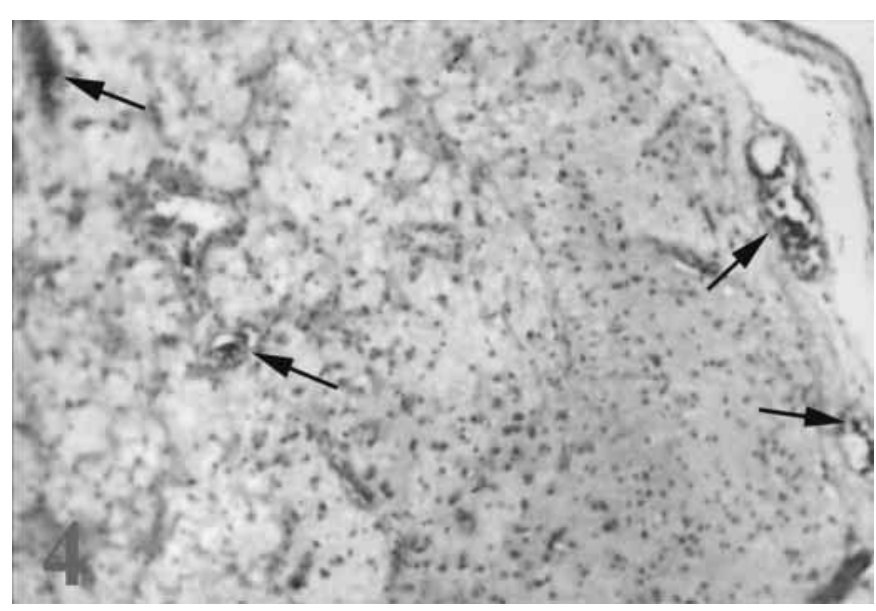

Figure 4. The cortical and meningeal blood vessels (arrows) filled with neoplastic cells and surrounded by small zones of spongy edema, reactive gliosis and foci of selective necrosis. HE, $\mathrm{x} 63$

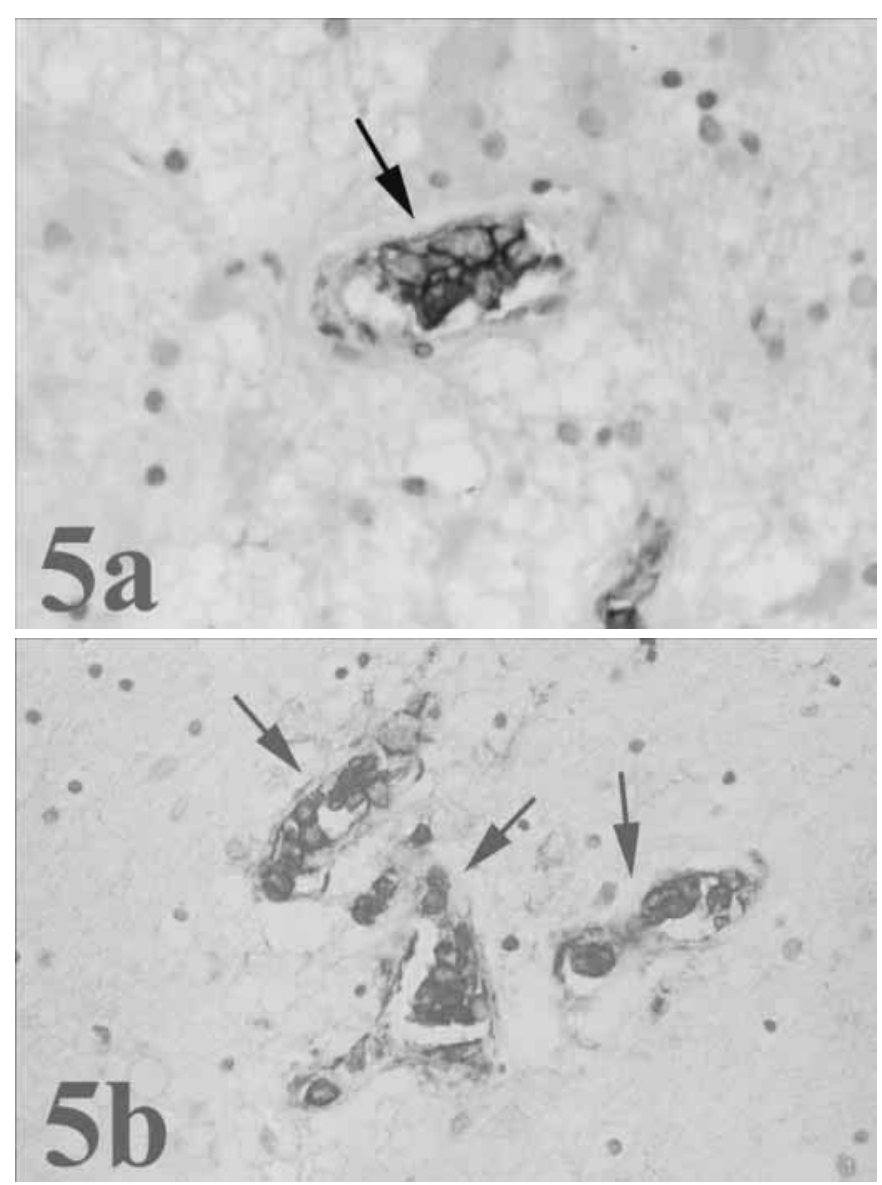

Figure 5. Immunohistochemically, neoplastic cells show strong positivity for a) the leukocyte common antigen, and b) the B-cell marker (CD20); a) x400, b) x400

\section{DISCUSSION}

We present a case of IVL in a 51-year-old woman with dominant neurological disturbances in clinical picture. Immunohistochemical analyses demonstrated that this neoplasm was of B-cell line being positive for LCA and B-cell antigen CD20 and negative for T-cell markers CD45R0 and CD3.
The clinical symptoms and signs of intravascular large cell lymphoma are nonspecific, and clinical course is usually rapid, as was shown in our case. Most patients present fever of unknown origin and nonspecific cutaneous and neurological manifestations. The typical appearance is erythematous or violet plaques mainly on the trunk and lower legs. However, cutaneous manifestations in our case were absent and a biopsy was not done because of absence of symptomatic or swollen tissues.

Majority of the patients have been diagnosed at autopsy as well as present case, although an antemortem diagnosis of IVL can be established by biopsy of different organs, first of all skin and brain including stereotaxic brain biopsy (9).

Muscle biopsy seems a safe and useful alternative to CNS biopsy particularly in neurological form of IVL $(10,11)$. In a few individual cases diagnosis has been made by renal (12), testicular (13), kidney allograft (14) biopsy and by prostatectomy, cholecystectomy (15) and appendectomy (16). Bone marrow aspiration and biopsy, as well as peripheral blood smear may be useful in the diagnosis of B-cell IVL especially when clinical presentation is restricted to fever of unknown origin with reactive hemophagocytic syndrome (17). However, in many cases findings in bone marrow and peripheral blood smear have been inconspicuous and not diagnostic.

IVLs are clinically and immunophenotypically heterogeneous and may represent more than one pathogenetic entity $(5,7)$. IVL is predominantly of B-cell lineage, but occasional cases of T-cell lineage IVL involving almost exclusively the skin and extremely rarely other systems or organs have been described (18). The Tcell origin of the IVL suggests an association with Epstein-Barr virus infection $(E B V)$, but these results are controversial too $(5,8,18)$ and must be checked and confirmed by further studies. Usually IVL as a particular form of lymphoma represents a diagnostic problem as it only rarely shows nodal or extranodal mass lesions. In our case no organ was found to have a mass and no lymphadenopathy was detected. The hallmark of IVL is the affinity of the lymphoma cells for the intravascular space of certain types of blood vessels without homing to lymphoreticular organs, such as the lymph nodes, bone marrow spleen and liver, as occurs in other lymphomas. The mechanisms that mediate this phenomenon are still unknown.

It is well known that immunosupression is associated with increased risk of lymphoproliferative disorders and it is conceivable that IVL arise in the background of immunosupression. Several case reports of IVL occurring in AIDS patients $(4,16,20,21)$ and in renal allograft recipients (14) have been reported.

Clinical manifestations of the disease are various and are due to multifocal occlusion of small vessels by tumor cells. The most 
characteristic sites of involvement are skin and central nervous system. The clinical presentation most commonly includes neurological disturbances, mental status changes, fever of unknown origin, skin changes and occasionally cough or shortness of breath $(11,15)$. All these symptoms and signs are nonspecific and clinical course is usually rapid, often fatal, an ante mortem diagnosis is difficult and can be made only by a biopsy. As this form of lymphoma is potentially treatable and even curable if chemotherapy is initiated early, histopathological diagnosis is mandatory. Correlation of clinical feature and post mortem pathological findings in reported cases as well as in present case show that absence of clinical manifestations in an organ does not mean lack of microscopic pathological changes. It means that a biopsy of such organ can reveal exact diagnosis in many cases, even in a case of cerebral form of IVL. It seems certain that early diagnosis is essential if therapeutic intervention is to be successful $(5,11,15)$.

\section{REFERENCES}

1. Bhawan J, Wolff SN, Ucci AA, Bhan AK. Malignant lymphoma and angioendotheliomatosis: one disease. Cancer 1985;55:570-6.

2. Carrol TJ, Schelper RL, Goeken JA, Kemp JD. Neoplastic angioendotheliomatosis: immunopathologic and morphologic evidence for intravascular malignant lymphomatosis. Am J Clin Pathol 1986;85:169-75.

3. Sheibani K, Battifora H, Winberg CD, Burke JS, Ben-Ezra J, Ellinger GM. Further evidence that "malignant angioendotheliomatosis" is an angiotropic large-cell lymphoma. N Engl J Med 1986;314:943-8.

4. Dožić S, Šuvaković V, Cvetković D, Jevtović Dj, Skender M. Neoplastic angioendotheliomatosis (NAE) of the CNS in a patient with AIDS subacute encephalitis, diffuse leucoencephalopathy and meniongo-cerebral cryptococcosis. Clin Neuropathol 1990;9(6):284-9.

5. Yagappan S, Coupland R, Arber D, Wang N, Miocinovic R, Raymond R et al. Angiotropic lymphoma: An immunophenotypically and clinically heterogeneous lymphoma. Mod Pathol 2001;14:1147-56.

6. Pfleger L, Tappeiner J. Zur Kentnis der System-Endotheliomatose der cutanen Blutgefaese. Hautarzt 1959;10:359-63.

7. Khalidi HS, Brynes RK, Browne $\mathrm{P}, \mathrm{Koo} \mathrm{CH}$, Battifora H, Medeiros LJ. Intravascular large B-cell lymphoma: the CD5 antigen is expressed by a subset of cases. Mod Pathol 1998;11:983-8.

8. Kanda M, Suzumiya J, Ohshima K, Tamura K, Kikuchi M. Intravascular large cell lymphoma: clinicopathological, immunohistochemical and molecular genetic studies. Leuk Lymhoma 1999;34(5-6):569-80.

9. Schlote W, Janzen CWR, Bockenheimer S, Berkefeld W, Marouardt. Intravascular malignant lymphoma (ex malignant angioendotheliomatosis): diagnosis by stereotactic brain biopsy. Clin Neuropathol 1997;16(5):285.

10. Suzuki S, Koizumi Y. Angiotropic lymphoma diagnosed by muscle biopsy. Intern Med 1997;36:304-7.

11. Nakahara $T$, Saito $T$, Muroi $A$, Sugiura $Y$, Ogata $M$, Sugiyama $Y$ et al. Intravascular lymphomatosis presenting as an ascending cauda equina: conus medullaris syndrome: remission after biweekly CHOP therapy. J Neurol Neurosurg Psychiatry 1999;67:403-6.
12. Axelsen RA, Laird PP, Horn M. Intravascular large cell lymphoma: diagnosis on renal biopsy. Pathology 1991;23:241-3.

13. Van Droogenbroeck J, Altintas S, Pollefliet Schroyens W, Berneman Z. Intravascular large B-cell lymphoma or intravascular lymphomatosis: report of a case diagnosed by testicle biopsy. Ann Hematol 2001;80(5):316-8.

14. Ghorbani RP, Shokouh-Amiri H, Gaber LW. Intragraft angiotropic large-cell Iymphoma of $\mathrm{T}$ cell type in a long-term renal allograft recipient. Mod Pathol 1996;9:671-6.

15. DiGiuseppe JA, Hartmann DP, Freter C, Cossman J, Mann RB. Molecular detection of bone marrow involvement in intravascular lymphomatosis. Mod Pathol 1997;10:33-7.

16. Malicki DM, Suh YK, Fuller GN, Shin SS. Angiotropic (intravascular) large-cell lymphoma of T-cell phenotype presenting as acute appendicitis in a patient with acquired immunodeficiency syndrome. Arch Pathol Lab Med 1999;123:335-7.

17. Dufau JP, Le Tourneau A, Molina T, Le Houcq M, Claessens YE, Rio B et al. Intravascular large B-cell lymphoma with bone marrow involvement at presentation and haemophagocytic syndrome: two Western cases in favour of a specific variant. Histopathology 2000;37:509-12.

18. Au WY, Shek WH, Nicholls J, Tse KM, Todd D, Kwong YL. T-cell intravascular lymphomatosis (angiotropic large cell lymphoma): association with Epstein-Barr viral infection. Histopathology 1997;31:563-7.

19. Dunphy C. Primary cutaneous angiotropic large-cell lymphoma in a patient with acqired immunodeficiency syndrome. Arch Pathol Lab Med 1995:119:757-9.

20. Hsiao CH, Su IJ, Hsieh, Huang SF, Tsai TF, Chen MY, How SW. Epstain-Barr virus-associated intravascular lymphomatosis within Kaposi's sarcoma in an AIDS patient. Am J Surg Pathol 1999;23:482-7.

21. Angeli G, Gobber M, Castri M, Carco F. Angiotropic large-cell lymphoma of the CNS in AIDS: description of a case. Clin Neuropathol 1994;13:142.

\section{Notice}

As agreed by authors and Editor-in-Chief key words in this paper are not cited according to $\mathrm{MeSH}$. 